\title{
COMUNIDADE E POLÍTICA
}

COMMUNITIE AND POLITICS

\author{
Gisele Silva Rodrigues ${ }^{1}$ \\ ${ }^{1}$ Universidade Federal de Goiás (UFG), Goiânia, GO, Brasil \\ Correspondência para: Gisele Silva Rodrigues (ggiselerodrigues@gmail.com) \\ doi: 10.12957/geouerj.2018.29420 \\ Recebido em: 29 set. 2017 | Aceito em: 22 ago. 2018
}

SCREENED BY $\checkmark$ iThenticate

\section{RESUMO}

A comunidade é construída a partir da integração e das diferentes trocas entre coletividades. Como forma humana de agrupamento, são caracterizadas por dois elementos centrais: a política e o espaço. Com a modernidade, a dependência do que há fora delas se sobrepõe ao que há dentro delas, onde os atores hegemônicos renovam as relações sociais, os meios de produção e o próprio entendimento sobre esses espaços. As ciências humanas também são responsáveis por propagar diferentes concepções sobre o conceito de comunidade e suas aplicações. No Brasil, as relações políticas na conformação das sociedades se sobressaem. 0 autoritarismo das classes hegemônicas imposto na convivência e o discurso produzido com base no local, escondem os conflitos vividos nas comunidades e impedem a ação política interna e externa da população. Este artigo discute essas questões a partir de revisão teórica de autores que trabalham o tema e que o utilizam para explicar uma certa realidade local. Ressalta-se a necessidade de uma leitura política e histórica acerca da forma como as comunidades se espacializam, sua dinâmica e transformações.

Palavras-chave: Comunidade. Política. Espaço. Integração. Modernidade.

\section{ABSTRACT}

The community is built from the integration and different exchanges between collectives. As a human form of groupment, it is defined by two central elements: politics and space. Thus, with modernity, the dependence from what is outside outweighs what is within, where the hegemonic actors manage to renew the social relations, the means of production and even the understanding about these spaces. Human sciences are also responsible in reproducing different views about the concept of community and its' applications. In Brazil, the political relations stand out on the conformation of communities. The authoritarianism of hegemonic classes imposed in the daily living and the discourse based on local relevance hide the conflicts lived within the communities and hinder internal and external political action of the populace. This paper discusses these questions from a theorical review of authors who work with the theme in order to explain a given local reality. It is stressed the necessity of a political and historical analysis about how the communities spatialize, their dynamics and transformations.

Keywords: Communitie. Politics. Space. Integration. Modernity.

\section{INTRODUÇÃO}

Para a política, como variável-chave para explicar as relações sociais externas e internas da comunidade, é dada uma importância reduzida. Nos estudos acadêmicos, principalmente, na Antropologia, História e Sociologia, que influenciam na abordagem teórica e empírica da Geografia, o aspecto político da comunidade tem sido pouco explorado. As análises contemporâneas são baseadas 
nas abordagens cultural, social, econômica e/ou da política vinculada à população. Uma das dificuldades quando se analisa geograficamente a comunidade é que os estudos já feitos são verticalizados, isto é, abordam as comunidades como um local estável, sem conflitos internos e a partir da necessidade que os seres humanos têm de ter um lugar para construções de identidades. Porém, a realidade espacial em que se insere a comunidade pode ser melhor apreendida a partir da compreensão das mudanças históricas e políticas. Analisar, portanto, a relação entre comunidade e política não é uma tarefa difícil, desde que se considere que relações sociais da comunidade implicam em ações políticas de atores, pertencentes ou não à comunidade, que é palco de diferentes interesses internos e externos.

A escala local dos fenômenos comunitários é referência e diferenciação necessária para o entendimento da ação dos seus atores políticos, no entanto, na compreensão teórica e empírica desses fenômenos, não deve restringir-se à localidade. Bourdin (2001, p. 26) atribui ao local "uma espécie de vulgata" que postula, na academia e na sociedade em geral, "a existência de uma realidade local, ao menos específica no mais irredutível, referente a todos os aspectos da vida em sociedade", que seria a matriz da sociabilidade, valorização de elementos em comum e a exaltação que as especificidades locais são instrumentos de estratégia social ou resistência. Para Santos (1994, p. 18-19), “cada lugar, porém, é ponto de encontro de lógicas que trabalham em diferentes escalas, reveladoras de níveis diversos, e às vezes contrastantes". Por isso, comunidades apresentam-se instáveis e dinâmicas no convívio de atores que atuam em diferentes escalas no processo histórico e criam poder político influenciando a sua conformação geográfica.

A ciência geográfica se depara com o desafio de entender a comunidade como fenômeno espacial. É preciso pensar: como os autores têm participado do debate sobre a comunidade? Para tentar responder a esta indagação, considerando o contexto histórico, apresentam-se três questões para orientar a reflexão: qual o significado de comunidade? Qual é o seu grau de autonomia? Quais transformações espaciais ocorrem no território em que se insere a comunidade? Neste estudo, objetiva-se entender teórica e empiricamente a comunidade a partir da política. 


\section{Escala e comunidade}

A palavra "comunidade" é proveniente do grego arcaico e significa "pólis" (ARISTÓTELES, [19--], p. 37). Como o homem se realiza como ser político quando vive em comunidade, é nela que ocorre a prática da cidadania. Traduzida para o Latim "communĭtãs" significa I: "Sentido próprio: comunidade, conformidade, instinto social, sociabilidade"; II: "sentido figurado: afabilidade, cortesia", que embora sejam características da vida comunitária, não contêm o aspecto político (MAGNE, 1961, p. 181). No dicionário de Língua Portuguesa é um substantivo feminino, "estado ou qualidade das coisas materiais ou das noções abstratas comuns a diversos indivíduos; [...] conjunto de habitantes de um mesmo Estado ou qualquer grupo social cujos elementos vivam numa dada área, sob um governo comum e irmanados por um mesmo legado cultural e histórico" (HOUAISS; VILLAR, 2009, p. 509). Por referir-se à qualidade do que é comum a diversos indivíduos e que, portanto, formam uma unidade, é uma expressão pleonástica, pois em todo grupo os indivíduos que mantêm alguma relação, mesmo que no sentido virtual como ocorre na sociedade contemporânea, tem certa característica em comum que o aglutina.

No Dicionário de Filosofia Abbagnano (2000, p. 162), a definição de comunidade é dividida em antes e depois do Romantismo. No período em que antecede o Romantismo, é descrita por Kant como: "a da ação recíproca, e também a terceira analogia da experiência (ou princípio da comunidade) assim expressa: 'Todas as substâncias, na medida em que podem ser percebidas no espaço como simultâneas, estão entre si em ação recíproca universal'." A partir do Romantismo, que ocorre com maior intensidade no início do século XIX devido à Revolução Francesa, a palavra comunidade foi utilizada pela primeira vez para contrapor dois mundos. Abbagnano (2000, p. 162) afirma: "comunidade foi contraposta à sociedade numa obra de Ferdinand Tönnies, Comunidade e Sociedade, publicada em 1887." A palavra comunidade, para Martins (1973, p. 32), surge "quando a matriz de existência é a sociedade", dentro do "confronto das duas noções". A partir de então, comunidade passa a significar o vínculo local; já a sociedade consiste nas relações externas. Essa abordagem influenciará as ciências humanas, onde os dois mundos são diferentes, mas sofrem alterações um do outro e se correlacionam, como campo e cidade, rural e urbano. 
No sentido de comunidade, Aristóteles ([19--], p. 15) chama a atenção para a existência de uma relação intrínseca entre ela e o homem, pois o homem "sabe discernir o bem do mal, o justo do injusto", sendo "o homem um animal político" é ele o responsável por uma vida plena em comum com os demais cidadãos. A virtude dos homens de bem é a "virtude do bom cidadão" na cidade, que representa valores comunitários para a vida cívica. Já Arendt (2002, p. 7) associa política à liberdade, diferentemente de Aristóteles para quem a política estaria centrada em cada homem de maneira natural - o ser político. A autora afirma que a política "baseia-se na pluralidade dos homens" e existe para regular o "convívio entre diferentes" na sociedade para que possam viver em comunidade. Percebe-se que o termo política associa-se com comunidade por tratar-se da ação de atores na manutenção das relações estabelecidas.

Com o advento da sociedade moderna a comunidade torna-se local de mudanças e de dependência externa. Para Giddens (1991, p. 11, grifos do autor), “'modernidade’ refere-se a estilo, costume de vida ou organização social que emergiram na Europa". Em escala local, comunidade torna-se "fantasmagórica", por obter influências da escala global, do externo e se alterar. Haesbaert (2006, p. 36, grifos do autor), sobre a modernidade, conclui que ela "é concebida, antes de mais nada, como a era da racionalidade, da tecnocracia e, portanto, do 'controle social'." Os espaços comunitários passam por um "esvaziamento do tempo" e "esvaziamento do espaço" no "desencaixe" de relações, que são diferentes dos que já haviam vivenciado (GIDDENS, 1991, p. 26). No sentido de comunidade, quando elas passam a obedecer a essa lógica racionalista, contraria-se o tempo e espaço da vida em comum em que há elementos com duração diferente, por exemplo, ocorrendo quando necessário e/ou afetam apenas o espaço local.

Diante dessa permanente desintegração e mudança, ser moderno é tudo aquilo que afasta o indivíduo de viver em comunidade como ter certa autonomia e o leva a "sentir-se fortalecido pelas imensas organizações burocráticas que detém o poder de controlar e frequentemente destruir comunidade, valores e vidas", como corrobora Berman (1986, p. 14). A modernidade pulveriza um sentimento de "paraíso perdido" que havia na comunidade por causa da dificuldade de manter uma unidade e entendimento da população que dela faz parte e, principalmente, “a fronteira entre o 'dentro' e o 'fora' não pode mais ser estabelecida e muito menos mantida", nas palavras de Bauman (2003, p. 18-19, 
grifos do autor). A rotina da comunidade já não serve por ela ser autônoma e por manter vínculos humanos, é necessário adaptar-se ou inserir-se em relações de trabalho repressivas e conflituosas, máquinas e utensílios, agora controladas por atores que detém o poder político e econômico local.

Os estudos de Buber (2013) e os de Fernandes (1972, 1973) contêm debates sobre a vida comunitária. O primeiro autor, filósofo humanista, discute em sua obra a experiência dos kibbutzim (comunidades agrárias) em Israel. O segundo autor, sociólogo, sintetiza em suas obras as formações comunitárias, no caso do Brasil afirma a existência de cinco formações: a aldeia tribal, a pequena comunidade, as vilas, a cidade tradicional e a cidade moderna. Nas ciências sociais brasileira, Martins (1973, p. 30-31, grifos do autor) afirma a existência de três concepções para comunidade: 1) vinculada a base local. Na sociologia americana comunidade é "sinônimo de sociedade local". Na sociologia clássica europeia há o entendimento de "comunidade de sangue e a comunidade de espírito"; 2) "como forma social utópica presente nos projetos que norteiam movimentos sociais". 3) "numa perspectiva de reconstrução sociológica da realidade social, isto é, pode constituir-se em método".

$\mathrm{Na}$ ciência geográfica predomina o primeiro conceito citado por Martins (1973) aplicado a comunidades tradicionais formadas a partir das relações de vizinhança, solidariedade, vínculo com o local (rural) e pertencimento, portanto, influenciado tanto pela sociologia clássica europeia quanto pela americana. Considerando-se que os dois primeiros conceitos citados por Martins (1973) trazem características de laços afetivos, é possível entender o que Bauman (2003, p, 7, grifos do autor) afirma: "a palavra 'comunidade' sugere coisa boa". O autor esclarece que essa palavra possui "significados e sensações" que os seres humanos almejam e a autonomia local que existiu. Assim, para este autor, o conceito de comunidade como uma realidade imaginada é o segundo citado por Martins (1973). Essa comunidade existia em tempos pretéritos, foi perdida e é buscada na contemporaneidade pelos indivíduos para se sentirem seguros, estando, portanto, para Bauman (2003), no tempo futuro. Já para Williams (2011, p. 182), comunidade pertence apenas ao passado, pois "as cercas e os muros, os novos direitos expressos no papel, representavam a declaração formal do novo poder constituído." 
Para este último autor, o que restou foram "comunidades marginais", que necessitam de se redefinirem constantemente, mas que nunca mais serão "comunidades genuínas".

Mesmo situadas localmente, tendo contextos específicos da ação política de seus membros, os indivíduos pertencentes a uma comunidade "contribuem para [...] influências sociais que são globais em suas consequências e implicações", nas palavras de Giddens (2002, p. 9). No jogo dialético entre o local e o global é que se reorganiza o espaço, recombinando distância e proximidade na vida comunitária. Vive-se a realidade em que "tudo que é sólido desmancha no ar", na expressão popularizada por Berman (1986), ou a "modernidade líquida" de Bauman (2001). Para Berman (1986, p. 97, grifos do autor), “[...] 'tudo o que é sólido' - das roupas sobre nossos corpos aos teares e fábricas que as tecem, [...] às vilas e cidades, regiões inteiras e até mesmo as nações que as envolvem - tudo isso é feito para ser desfeito amanhã".

Apesar de não se poder prever os efeitos das ações da modernidade na comunidade (com qualquer conceito que se aplique a elas) porque o mundo moderno está em constante e veloz alteração, o espaço é "testemunha e veículo dessa dinâmica" (HAESBAERT, 2006, p. 81). Dos fatos e fenômenos da moderna sociedade burguesa capitalista europeia talvez o que mais afetou as comunidades (e seus conceitos) seja a propriedade da terra. Mesmo na Europa feudal as comunidades tiveram usos da terra conforme os interesses da coletividade. Conforme Williams (2011, p. 167), na Europa, especificamente na Inglaterra, houve uma pressão para transformar a terra comunal em privada. 0 autor reconhece a importância dos "cercamentos" na transição de uma sociedade rural para urbana no último quartel do século XVIII, "ao abolirem as últimas aldeias onde vigorava o sistema de campo aberto e os direitos comuns". Para viabilizar esse processo político, econômico e territorial, deixando-o público e legalmente documentado, os proprietários de terras tinham o apoio parlamentar e até mesmo foram criadas inúmeras leis para que terras fossem apropriadas por eles.

Nesse processo de privatizar a terra, a modernidade, marcada pela ação de atores hegemônicos na expansão capitalista, produz seus territórios que, diante do contexto histórico, tornam o local em "supermoderno", como corrobora Bourdin (2001, p. 199). Para esse autor, identificou-se no local os 
elementos necessários para se qualificar no discurso uma definição do que vem a ser a vida comunitária. São eles: "fortes interações entre seus membros no cotidiano, proximidade dos modos e/ou estilos de vida, acentuadas referências comuns (identitárias, religiosas, sociais), bem como pela capacidade de exprimir esta proximidade em instituições". Essas são as características relacionadas ao apego à escala local para reafirmar o dualismo da sociedade contemporânea.

Apesar do processo de colonização e surgimento do Brasil ser contemporâneo e até mesmo produto desse contexto europeu, ele não se repetiu aqui exatamente como lá. As comunidades brasileiras foram sendo construídas e reconstruídas em função das ações específicas que nelas ocorriam, dos seus próprios contextos históricos. Nas palavras de Bourdin (2001, p. 186), "a localização produz o lugar, e a ação especializada cria os 'produtores'. Regular (principalmente através da gestão) a interação dos atores que localizam sua ação constitui, pois, um dos meios de produzir o lugar". O Estado é que regula, ao qual a modernidade, na Europa, também deu novas feições, o que não diminuiu sua importância na conformação do espaço nos demais continentes colonizados. Para Raffestin (1993, p. 40), o Estado "é um ator sintagmático por excelência", por organizar e controlar os territórios em que estão inseridas as comunidades.

\section{Autonomia e política}

Os primeiros agrupamentos humanos sedentários não possuíam total autonomia em relação a outros do mesmo espaço, mesmo porque não viviam completamente isolados uns dos outros. E é justamente a dependência existente entre elas que promove a sua integração espacial. À medida que se desenvolviam as técnicas e aumentava-se a produção de bens, conforme Castells (2000, p. 42, grifos do autor), “um sistema de divisão e de distribuição se desenvolve, como expressão e desdobramento de uma capacidade técnica e de um nível de organização social." Santos (1994, p. 20) vê a técnica "como enigma que [...] comanda nossa vida, impõe relações, modela nosso entorno, administra nossas relações com o entorno", tendo em vista a necessidade de troca entre coletividades. O excedente produzido, em quantidade e variedade, possibilitava as trocas entre comunidades, diminuindo a autossuficiência de cada uma e promovendo as especializações, conforme os recursos naturais e 0 
trabalho humano com que cada uma contava. Ao mesmo tempo, novos desejos e necessidades, provenientes da sociedade que se formava, foram sendo incorporadas à vida comunitária.

No Brasil, desde o século XX as denominações e significados oficiais estão relacionadas às suas localizações (rural ou urbana). No Quadro 1 consta as denominações utilizadas pelo Instituto Brasileiro de Geografia e Estatística (IBGE), organizado a partir da área que ocupam.

\begin{tabular}{|c|c|}
\hline Área & Significado territorial \\
\hline$\frac{\frac{8}{3}}{\frac{3}{z}}$ & $\begin{array}{l}\text { "Localidade que tem a característica definidora de Aglomerado Rural Isolado e que } \\
\text { possui caráter privado ou empresarial, estando vinculado a um único proprietário } \\
\text { do solo (empresas agrícolas, indústrias, usinas, etc.)" (IBGE, 2010, p. 33). }\end{array}$ \\
\hline 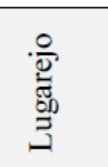 & $\begin{array}{l}\text { "Localidade sem caráter privado ou empresarial, que possui característica } \\
\text { definidora de Aglomerado Rural Isolado e não dispõe, no todo ou em parte, dos } \\
\text { serviços ou equipamentos enunciados para o povoado." (IBGE, 2010, p. 33). }\end{array}$ \\
\hline 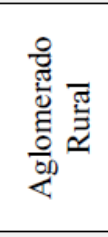 & $\begin{array}{l}\text { "Localidade situada em área não definida legalmente como urbana e caracterizada } \\
\text { por um conjunto de edificações permanentes e adjacentes, formando área } \\
\text { continuamente construída, com arruamentos reconhecíveis ou dispostos ao longo de } \\
\text { uma via de comunicação." Os aglomerados se subdividem em dois grupos: 1) } \\
\text { Aglomerados Rurais de Extensão Urbana, e 2) Aglomerados Rurais Isolados. } \\
\text { (IBGE, 2010, p. 33). }\end{array}$ \\
\hline 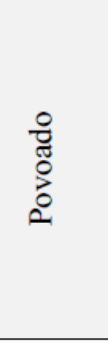 & $\begin{array}{l}\text { "Localidade que tem a característica definidora de Aglomerado Rural Isolado e } \\
\text { possui pelo menos um (1) estabelecimento comercial de bens de consumo frequente } \\
\text { e dois (2) dos seguintes serviços ou equipamento: um (1) estabelecimento de ensino } \\
\text { fundamental, do } 1^{\circ} \text { ao } 9^{\circ} \text { ano, em funcionamento regular; um (1) posto de saúde, } \\
\text { com atendimento regular e um (1) templo religioso de qualquer credo, para atender } \\
\text { aos moradores de aglomerados e/ou áreas rurais próximas; corresponde a um } \\
\text { aglomerado sem caráter privado [...] e cujos moradores exercem atividades } \\
\text { econômicas quer primárias, terciárias ou, mesmo secundárias, na própria localidade } \\
\text { ou fora dela." (IBGE, 2010, p. 33). }\end{array}$ \\
\hline$\frac{\pi}{7}$ & $\begin{array}{l}\text { "Localidade com o mesmo nome do Distrito a que pertence (sede distrital) e onde } \\
\text { está sediada a autoridade distrital, excluídos os distritos das sedes municipais." } \\
\text { (IBGE, 2010, p. 32). }\end{array}$ \\
\hline 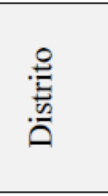 & $\begin{array}{l}\text { "São unidades administrativas dos municípios. Sua criação, desmembramento ou } \\
\text { fusão dependem de leis municipais, que devem observar a continuidade territorial e } \\
\text { os requisitos previstos em lei complementar estadual. Podem ser subdivididos em } \\
\text { unidades administrativas denominadas subdistritos, regiões administrativas, zonas } \\
\text { ou outra denominação específica." (IBGE, 2011, p. 21). }\end{array}$ \\
\hline$\frac{\frac{0}{2}}{\frac{2}{2}}$ & $\begin{array}{l}\text { "Os municípios constituem as unidades autônomas de menor hierarquia dentro da } \\
\text { organização político-administrativa do Brasil. Sua criação, incorporação, fusão ou } \\
\text { desmembramento dependem de leis estaduais, que devem observar o periodo } \\
\text { determinado por lei complementar federal e a necessidade de consulta prévia, } \\
\text { mediante plebiscito, às populações envolvidas, após divulgação dos estudos de } \\
\text { viabilidade municipal, apresentados e publicados na forma da lei. Os municípios } \\
\text { são regidos por leis orgânicas, observados os princípios estabelecidos na } \\
\text { Constituição Federal e na constituição do estado onde se situam, e podem criar, } \\
\text { organizar e suprimir distritos." (IBGE, 2011, p. 20-21). }\end{array}$ \\
\hline
\end{tabular}

Quadro 1. Significado territorial político-administrativo da comunidade - Brasil.Fonte:IBGE (2010, 2011). Organizado pela autora. 
Mesmo as mais isoladas, distantes de certos focos urbanos relativamente complexos, as primeiras comunidades se distinguem historicamente das comunidades indígenas, pois não tinham autonomia, uma vez que para aquele modo de vida não eram todos obtidos nas próprias comunidades. As comunidades indígenas não se constituem como base da formação da sociedade brasileira, criada por meio do processo de colonização, tendo em vista que elas já se encontravam no território, como corrobora Fernandes (1972) ao descrever sobre as diferentes formações comunitárias existentes no país. Quanto às demais comunidades que dependiam do meio externo, desde o princípio, foram influenciadas, inclusive por símbolos vinculados a brancos, negros e índios (religião, língua, culinária e concepções) difundidas em outros espaços. Um estudo que retrata a comunidade e a influência do que ela absorve está no trabalho de Cândido (1979), ao tratar da cultura caipira paulista, composta por sitiantes, posseiros e agregados em uma economia de autoconsumo a partir de uma população móvel, livre, branca ou mestiça (branco com índio e com pouco sangue negro).

No caso das primeiras comunidades brasileiras elas trocavam certos produtos com outras localidades, como alimentos e ferramentas produzidos em economias mais complexas e situadas fora do limite local. Mesmo quando a fabricação era local, eram réplicas rústicas de produtos difundidos pela sociedade moderna europeia. Produtos como, por exemplo, sal, açúcar e enxada eram dificilmente produzidos em uma mesma comunidade, necessitando-se de trocas entre elas e delas com as que já se formavam a partir, principalmente, do excedente produzido na terra. Essa dependência inicial não muda a estrutura organizacional, refere-se a "um novo sistema social, mas que não está separado do tipo rural, nem é posterior a ele, pois os dois estão intimamente ligados no âmago do mesmo processo de produção das formas sociais", nas palavras de Castells (2000, p. 42, grifos do autor). 0 autor ressalta que isso propicia o fenômeno urbano, a partir da "diferenciação do produto em reprodução simples e ampliada da força de trabalho, chegando a um sistema de distribuição e troca".

Há três fatos relacionados ao sistema de aquisição de terras e à instituição do mercado de trabalho na sociedade brasileira colonial e império que possibilitam entender como esse processo ocorreu espacialmente, ocasionando a dependência que as comunidades têm das sociedades que as cerca e da qual elas fazem parte. São eles: 1) sistema de sesmaria, 2) universalização jurídica da propriedade 
privada pela Lei de Terras de $1850^{1}$ e 3 ) implantação do trabalho livre pela Lei Áurea em $1888^{2}$. Desse modo, a terra é adquirida pela participação no sistema político-administrativo nacional, o qual favorece, desde o princípio, o fazendeiro. A outra possibilidade de acesso à terra é a posse, a partir da ocupação, que favorece camponeses e posseiros. Mas, devido à manipulação política de instituições administrativas e jurídicas para legalizar a terra, prevaleceram os direitos às terras por propriedades particulares. De acordo com Martins (1986, p. 12), quando ocorre o fim do trabalho escravo, devido à "crise do cativeiro", também ocorre a "separação do trabalhador de sua força de trabalho e nela se fundava a sua sujeição ao capital personificado no proprietário da terra", cuja riqueza tinha sido acumulada por meio do trabalho escravo.

Ianni (2004, p. 21) analisa a ideia do chamado "Brasil moderno" e destaca que entre 1.888 e 1.889 o país tentou entrar no ritmo mundial, favorecendo a imigração, adotando a constituição federativa e promovendo o povoamento de terras devolutas, tendo como premissa o "branqueamento da população para acelerar o esquecimento dos séculos de escravismo." Pode se aplicar a esse contexto a afirmação que "muitos núcleos urbanos testemunham um esforço lento e diversificado de interiorização ou, quando menos, de ocupação", nas palavras de Marx (1980, p. 16). Sobre esse processo de urbanização no país, ressalta-se ainda que a toponímia revela a importância do sítio urbano, a escolha do local e a motivação funcional para o surgimento do agrupamento humano. Houve a construção de capelas para formação de povoados, onde se concentraram as atividades religiosas, reunindo a população e que viabilizou a formação da malha urbana. Conforme Marx (1988, p. 7), “o espaço urbano público no Brasil evoluiu lentamente do sagrado ao profano", devido à influência da Igreja Católica na urbanização do país.

É nesse processo de surgimento de núcleos urbanos em uma sociedade baseada nas atividades econômicas dos latifúndios monocultores e exportadores - mas que para sua subsistência dependiam de atividades exercidas em pequenas glebas de terra, por trabalhadores livres que a relação assimétrica entre agregados e fazendeiros, historicamente, compõe a formação de comunidades conforme a

\footnotetext{
${ }^{1}$ A Lei no 601, de 18 de setembro de 1850, dispõe sobre as terras devolutas do império. (BRAZIL, 1850).

${ }^{2}$ A Lei $n^{0} 3.353$, de 13 de maio de 1888, declara extinta a escravidão no Brasil. (BRAZIL, 1888).
} 
determinação da modernidade. 0 fazendeiro era reconhecido localmente e no âmbito políticoadministrativo estadual ${ }^{3}$ e nacional pelo número de trabalhadores que utilizava e pela quantidade de terra que possuía, sendo responsável pela doação da terra para o surgimento do povoado. Leal (1978, p. 20), ao analisar os aspectos políticos dos municípios brasileiros, enfatiza que a Primeira República se baseia no "coronelismo", que "é sobretudo um compromisso, uma troca de proveitos entre o poder público [...] e a decadência da influência social dos chefes locais, notadamente dos senhores da terra." Para manter-se no poder, o coronel mantinha a população submissa: “é, pois, para o próprio 'coronel' que o roceiro apela nos momentos de apertura, comprando fiado em seu armazém para pagar com a colheita, ou pedindo dinheiro, nas mesmas condições, para outras necessidades” (LEAL, 1978, p. 24, grifos do autor). O coronel propiciava acesso ao médico, a passagem para a estrada de ferro e batizava os filhos dos agregados.

As relações entre parentes, vizinhos, amigos e o fazendeiro, também dono do comércio local na maioria das vezes, é que compõe o espaço político comunitário. O coronel muitas vezes mantinha também relações impessoais e não possuía nenhum vínculo comum com os demais membros da comunidade, mesmo assim, servia como intermediário entre a comunidade e o que era externo a ela. Nessa relação entre atores sociais diferentes, o conflito, inerente à convivência humana, mostra-se por meio da submissão, da violência e de acordos estabelecidos entre eles. O poder político é conferido ao coronel, a princípio, pela necessidade dos agregados de ter acesso à terra e de comprar no comércio local. Nas palavras de Castro (2005, p. 16), "na relação entre política - expressão e modo de controle dos conflitos sociais - e o território - base material e simbólica da sociedade", formam-se e transformamse as comunidades.

Esse sistema de poder político e econômico se estabeleceu absolutamente quando a relação entre coronel e agregados passou a ocorrer por mediação do voto e se reconfigurou socialmente no âmbito político municipal. Mesmo com as alterações jurídicas ao longo do processo histórico do país que

\footnotetext{
${ }^{3}$ Abrucio (1998, p. 17) corrobora sobre o papel dos governadores dos estados no processo político de interesses federalistas brasileiros. Parte da premissa de um "federalismo estadualista", o qual perpetuou no poder as oligarquias agrárias desde a Primeira República, denominadas pelo autor de "os barões da federação". Isso só foi possível a partir do poder político comunitário, onde se tinha os votos para manter tanto os coronéis locais quanto os governadores.
} 
conferiram menor ou maior importância aos municípios, permanecem sendo a estrutura federativa de menor esfera de poder. A comunidade torna-se regulada pelas normas político-administrativas e jurídicas do município. Independentemente da localização da comunidade (área rural ou área urbana), o município "é a expressão mais concreta do próprio conjunto do território e da sociedade brasileira - as diferenças de tamanho, densidade, riqueza, participação política, organização da sociedade local resultam da própria complexidade de ambos" (CASTRO, 2005, p. 135). A existência da comunidade passa, conforme Martins, (1982, p. 12), a vincular-se à "expropriação da terra" no campo e da "exploração do trabalho" nas cidades, além das péssimas condições de cortiços e favelas que caracterizam a violência empregada pela classe hegemônica.

Associado a esse processo histórico, o discurso que estabelece dualidades intransponíveis entre o rural/urbano, campo/cidade, comunidade/sociedade, atrasado/moderno e favela/cidade é utilizado para difamar a rotina e o modo da vida comunitário. Nas palavras de Martins $(1975$, p. 4), isso visa "propiciar as condições para transformar o caipira do estereótipo no cidadão das concepções urbanas", isto é, um consumidor de produtos necessários ou não, além de comportamentos urbanos. Mas nesse processo o Estado é um ator importante, pois investe em infraestrutura nos espaços, como ferrovias e rodovias em certos territórios, o que possibilita o avanço demográfico, a exploração dos recursos naturais e humanos e as formas superficiais de urbanização que transformam estilos de vida social baseados no comunitarismo em estilos de vida modernos.

Mesmo dispersas, de modo geral, as comunidades vão se mantendo ao longo das décadas no território nacional. Elas não desapareceram, tampouco está decretado o seu fim diante do processo de urbanização, transformações do campo e das modificações internas pelas quais passaram. Os seus princípios básicos de origem e formação comunitária parecem não ter sido tão mudados ao ponto de fazê-las se dissiparem da sociedade moderna/capitalista. Esses espaços ainda constituem-se por uma estrutura socioeconômica simples, o que lhes permitem adaptarem-se às variações das condições econômicas no âmbito local-regional, pois ainda que percam seu espaço, reterritorializam-se no campo ou na cidade. 


\section{CONSIDERAÇÕES FINAIS}

A palavra comunidade carrega consigo significados que reafirmam as necessárias relações sociais humanas, mesmo que virtuais, como ocorre na sociedade contemporânea. No âmbito da ciência geográfica, o desafio é compreender a comunidade como um fenômeno espacial a partir de seu contexto histórico, o que demanda partir dos processos e das ações que nela ocorrem e que ela sofre. Há um predomínio de estudos sobre a comunidade vinculada à abordagem teórica europeia e norte-americana de antropólogos, historiadores e sociólogos, que se limitam em níveis do que há de comum (lugar, religião, parentesco, vizinhança, cultura), com influência da escala local e da construção de identidades (com vínculo rural). Dessa concepção surge um discurso que propaga o lado positivo da vida em comunidade, como se em toda e qualquer comunidade humana não existissem conflitos. Compreendêlas a partir da estabilidade e reproduzir esse tipo de entendimento é mais fácil que inseri-las em dinâmicas sucessivas da ação de atores, internos e externos às comunidades.

Mudando-se o viés do entendimento, partindo em direção à compreensão dos processos de surgimento dos agrupamentos humanos e de suas relações com a sociedade moderna pela ação de atores, das leis e do poder político-administrativo municipal, torna-se possível admitir a pluralidade das comunidades e a política como variável-chave para a sua compreensão. Como são dinâmicas, as transformações que sofrem são constantes, e é preciso levar isso em consideração, bem como é preciso evitar os discursos que escondem os conflitos vivenciados interna e/ou externamente a elas. É preciso não tratá-las como se fossem e estivessem em mundos diferentes, mesmo porque os espaços e os tempos se integraram de tal forma que Santos (1994) propõe a existência de um espaço-tempo que tira da comunidade como característica peculiar, o local. Não há como saber até que ponto a comunidade está ou não na cidade, no campo ou no ciberespaço. Seus limites não são mais tão claros, como antes, o que mais importa é que a comunidade é composta por cidadãos, que podem fazer parte do poder político social.

\section{REFERÊNCIAS}

ABBAGnAnO, Nicola. Dicionário de filosofia. Tradução de Alfredo Bosi. 4 ed. São Paulo: Martins Fontes, 2000. p. $162-$ 163. 
ABRUCIO, Fernando Luiz. Os barões da federação: os governadores e a redemocratização brasileira. São Paulo: Hucitec, 1998. 253p.

ARENDT, Hannah. 0 que é política? Tradução Reinaldo Guarany. 3 ed. Rio de Janeiro: Bertrand Brasil, 2002. 240p.

ARISTÓTELES. A política. Tradução de Nestor Silveira Chaves. São Paulo: Escala, 19[--]. 284p. (Coleção Grandes Obras do Pensamento Universal - 16).

BAUMAN, Zygmunt. Modernidade líquida. Rio de Janeiro: Jorge Zahar, 2001. 258 p.

Comunidade: a busca por segurança no mundo atual. Tradução de Plínio Dentzien. Rio de Janeiro: Zahar, 2003.

$141 \mathrm{p}$.

BERMAN, Marshall. Tudo que é sólido desmancha no ar: a aventura da modernidade. Tradução de Carlos Felipe Moisés e Ana Maria L. Ioriatt. São Paulo: Companhia das Letras, 1986. 360p.

BOURDIN, Alain. A questão local. Tradução de Orlando dos Santos Reis. Rio de Janeiro: DP\&A, 2001. 237p.

BRAZIL. Decreto-Lei n. 601/1850. Dispõe sobre as terras devolutas do império. Disponível em: < http://www.planalto.gov.br/ccivil_03/Leis/L0601-1850.htm >. Acesso em: 22 set. 2016.

Decreto-Lei n. 3.353/1888. Declara extinta a escravidão no Brasil. Disponível em: <

http://www.planalto.gov.br/ccivil_03/leis/LIM/LIM3353.htm>. Acesso em: 22 set. 2016.

BUBER, Martin. Encontro com os clássicos - Um experimento que não falhou. Revista Território Autônomo / ReKro, n. 2 , p. 41-49, 2013. Disponível em: < http://rekro.webnode.com.br/revista-territorio-autonomo/numero-1/numero-2/>. Acesso em: 10 jun. 2017.

CÂNDIDO, Antonio. Os parceiros do rio bonito: estudos sobre o caipira paulista e a transformação dos seus meios de vida. São Paulo: Duas Cidades, 1979. 284p.

CASTELLS, Manuel. A questão urbana. Tradução de Arlene Caetano. Rio de Janeiro: Paz e Terra, 2000. 590p.

CASTRO, Iná Elias de. Geografia e política: território, escalas de ação e instituições. Rio de Janeiro: Bertrand Brasil, 2005. $299 \mathrm{p}$.

FERNANDES, Florestan. Comunidade e sociedade: leituras sobre problemas conceituais, metodológicos e de aplicação. São Paulo: Nacional/USP, 1973. 587p.

(Org.). Comunidade e sociedade no Brasil: leituras básicas de introdução ao estudo macro-sociológico do Brasil. São Paulo: Nacional/USP. 1972. 587p.

GIDDENS, Anthony. Modernidade e identidade. Tradução de Plínio Dentzien. Rio de Janeiro: Jorge Zahar, 2002. 233p. As consequências da modernidade. Tradução de Raul Fiker. São Paulo: UNESP, 1991. 177p.

HAESBAERT, Rogério. Territórios alternativos. 2. ed. São Paulo: Contexto, 2006. 186p.

HOUAISS, Antonio; VILLAR, Mauro de S. Dicionário Houaiss da língua portuguesa. Rio de Janeiro: Objetiva, 2009. p. 509-510.

IANNI, Octavio. A ideia de Brasil moderno. 3. ed. São Paulo: Brasiliense, 2004. 180p. 
IBGE. Instituto Brasileiro de Geografia e Estatística. Censo demográfico 2010. Características da população e dos domicílios - resultado do universo. Rio de Janeiro: IBGE, 2011. p. 20-21.

Glossário dos termos genéricos dos nomes geográficos utilizados no mapeamento sistemático do Brasil. Rio de Janeiro: IBGE, 2010. p. 32-33.

LEAL, Victor Nunes. Coronelismo, enxada e voto: o município e o regime representativo no Brasil. 2. ed. São Paulo: AlfaOmega, 1978. 276 p.

MAGNE, Augusto. Dicionário etimológico da Língua Latina: famílias de palavras e derivações vernáculas. Rio de Janeiro: Instituto Nacional do livro, 1961. p. 181-182.

MARTINS, José de S. 0 cativeiro da terra. 3 ed. São Paulo: Hucitec, 1986. 157p.

Expropriação e violência: questão política no campo. 2. ed. São Paulo: Hucitec, 1982. 181p.

Capitalismo e tradicionalismo: estudos sobre as contradições da sociedade agrária no Brasil. São Paulo: Pioneira, 1975. 161p.

A Imigração e a Crise do Brasil Agrário. São Paulo: Pioneira, 1973. 222 p.

MARX, Murillo. Nosso chão: do sagrado ao profano. São Paulo: Universidade de São Paulo, 1988. 219 p.

Cidade brasileira. São Paulo: Melhoramentos, 1980. 151p.

RAFFEStin, Claude. Por uma geografia do poder. Tradução de Cecília França. São Paulo: Ática, 1993. 269p.

SANTOS, Milton. Técnica, espaço, tempo: globalização e meio técnico-científico informacional. São Paulo: Hucitec, 1994. $190 \mathrm{p}$.

WILLIAMS, Raymond. 0 campo e a cidade: na história e na literatura. Tradução de Paulo Henrique Britto. São Paulo: Companhia das Letras, 2011. 531p. 